\title{
Inhibiting autophagy potentiates the antitumor efficacy of Euphorbia royleana for canine mammary gland tumors
}

\author{
Yu-Ya Huang ${ }^{1}$, Chia-Hung Chen², Chia-Hui Hsu', Tsun-Yung Kuo ${ }^{3}$, Cheng-Chi Liu', Albert Tai-Ching Liao ${ }^{1,4}$ and \\ Chen-Si Lin ${ }^{1,4^{*}}$ (i)
}

\begin{abstract}
Background: Canine mammary gland tumors (CMGTs) are the most common neoplasms in intact female canines and viewed as a suitable model for studying human breast cancers. Euphorbia royleana has been reported to have a variety of antitumor efficacies. We have prepared the crude extracts of E. royleana in ethanol and hexane solvents to evaluate the anti-tumor effects for CMGT in vitro and in vivo.

Results: The results showed that E. royleana could inhibit cell proliferation and colony formation in cMGT cells. The suppression of tumor cell growth resulted from necrosis and cell cycle arrest. Moreover, autophagy appears to play a critical role in E. royleana-mediated cell death by triggering cell apoptosis. The in vivo results also revealed that $E$. royleana treatment could reduce the size of solid tumors while exhibiting low toxicity in CMGT-bearing nude mice.

Conclusions: The anti-tumor mechanisms of E. royleana were firstly verified to show it would cause autophagic cell death, apoptosis, and cell cycle arrest in canine mammary tumor cells. The in vitro and in vivo findings in the present study revealed E. royleana has potential anticancer effects for the treatment of canine mammary gland tumors.
\end{abstract}

Keywords: Autophagic cell death, Apoptosis, Anti-tumor efficacy, Canine mammary tumors, Herbal medicine

\section{Background}

Canine mammary gland tumor (cMGT) is one of the commonest tumors diagnosed in old intact female canines. The epidemiological, histopathological, and clinical characteristics as well as the biological behaviors of cMGTs in female canines are similar to human breast cancer and viewed as an excellent comparative disease model $[1,2]$. Approximately $50 \%$ of the cases are diagnosed as malignant mammary carcinomas [3]. Old age,

\footnotetext{
* Correspondence: cslin100@ntu.edu.tw

'Department and Graduate Institute of Veterinary Medicine, School of Veterinary Medicine, National Taiwan University, No.1 Sec.4 Roosevelt Rd, Taipei 10617, Taiwan

${ }^{4}$ Animal Cancer Center, College of Bioresources and Agriculture, National Taiwan University, Taipei 10617, Taiwan

Full list of author information is available at the end of the article
}

mixed breed, and large size represent risk factors for malignancy [4]. Surgical resection remains the most widely accepted treatment option for cMGTs, and adjuvant therapies such as chemotherapy, hormonal therapy, and radiation therapy are necessary; however, the cancer still recurs at a $66 \%$ rate after surgery in cMGT cases [5]. Therefore, to investigate effective therapies is significant and crucial for mammary tumor-bearing dogs.

Euphorbia royleana is a medicinal shrub of Euphorbiaceae family. Various species in the family have been reported to be able to inhibit cancer development [6,7], including E. hebecarpa and E. microciadia against HeLa tumor cells, E. osyridea against bladder carcinoma cells, and E. cheiradenia against leukemia cell lines [8]. There are several ways to extract E. royleana, and each 
demonstrated different functions on tumor cells and the immune system [9]. The ethyl acetate fraction from the latex of E. royleana has considerable analgesic, antipyretic, anti-inflammatory, and immunosuppressive activity in animal models while its hexane fraction was proved to have antitumor effects $[8,10]$.

Cell death can result from necrosis, apoptosis, and autophagy; however, the role of autophagy in cancer cell death remains controversial. Autophagy appears to be tumor suppressive during cancer development but may contribute to tumor cell survival during cancer progression $[11,12]$. Many studies also showed inhibiting autophagy can enhance the therapeutic benefits of various cancer therapies [13-15].

This study aims to investigate the antitumor effects and mechanisms of $E$. royleana for canine mammary tumors. The functions of autophagic inhibitors on prohibiting cancer growth with E. royleana are also validated to define the potential role of autophagy in cMGT development. Our in vitro and in vivo findings have revealed the administration of E. royleana extracts possessed an efficient tumor suppression and could be a possibly therapeutic option for canine mammary cancers.

\section{Results}

\section{E. royleana extracts inhibited cell proliferation of $\mathrm{CMGT}$ cells}

To investigate the potential of the ethanol extract of E. royleana (X.E.E.) and hexane extract of E. royleana (X.H.E.) for cell growth inhibition of cMGTs, the antiproliferative effect of X.E.E. and X.H.E. in MPG and CMT1 cells was first measured. Cell viability was determined through WST1 assay. X.E.E. and X.H.E. inhibited cell growth in both cancer cell lines in a dose- and time-dependent manner (Fig. 1a). To determine whether the cell growth inhibition was due to cell death, we used trypan blue exclusion to find a dose- and time-dependent cell death was resulted after treating cMGT cell with X.E.E. and X.H.E.. Over $50 \%$ cell death of MPG cells treated with $20 \mu \mathrm{g} / \mathrm{mL}$ X.E.E. $10 \mu \mathrm{g} / \mathrm{mL}$ X.H.E was observed on day 3; over $50 \%$ cell death in CMT1 cells treated with $20 \mu \mathrm{g} / \mathrm{mL}$ X.E.E. or $10 \mu \mathrm{g} / \mathrm{mL}$ X.H.E. was observed on day 5 (Fig. 1b). These results demonstrated that X.E.E. and X.H.E. inhibited tumor cell growth by inducing the death of cMGT cells. The safety of $E$. royleana extracts for normal cells was subsequently validated. The treatment of normal cell lines containing both canine MDCK and non-human primate Marc145 and Vero cells with X.E.E. and X.H.E. revealed limited cytotoxicity (Table 1) at high concentrations and treatment time. The $\mathrm{IC}_{50}$ values implied that X.E.E and X.H.E. targeted only the tumor cells and were relatively safe for normal cells.

\section{E. royleana extracts reduced the colony formation of cMGT cells}

A 3D colony formation model was next used to further validate the tumor suppression ability of $E$. royleana extracts. MPG and CMT1 cells treated with $10 \mu \mathrm{g} / \mathrm{mL}$ X.E.E. or $5 \mu \mathrm{g} / \mathrm{mL}$ X.H.E. for 14 days exhibited fewer expanding colonies compared with the untreated control cells. The colony formation of MPG cells treated with $5 \mu \mathrm{g} / \mathrm{mL}$ X.H.E. in $5 \%$ FBS was significantly lower compared with control cells; MPG cells treated with $10 \mu \mathrm{g} / \mathrm{mL}$ X.E.E. or $5 \mu \mathrm{g} / \mathrm{mL}$ X.H.E. in the $0.5 \%$ FBS exhibited significantly lower colony formation (Fig. 2a \& c). The colony formation of CMT1 cells with or without $10 \mu \mathrm{g} / \mathrm{mL}$ X.E.E. or $5 \mu \mathrm{g} /$ $\mathrm{mL}$ X.H.E. revealed similar results (Fig. $2 \mathrm{~b}$ and $\mathrm{d}$ ). Therefore, E. royleana extracts significantly reduced the ability of clonogenic cell survival.

\section{E. royleana extracts induced necrotic death of CMGT cells}

X.E.E. and X.H.E. have been proved to induce the death of cMGT cells (Fig. 1). Therefore, the examination of the phenotypic consequences of cell death from E. royleana treatment of cMGT cells was crucial. Necrosis was detected by the release of LDH releasing assay. MPG and CMT1 cells with X.E.E. and X.H.E. elicited the release of LDH after 3 days of agonist application (Fig. 3a d). These data demonstrated that exposure to X.E.E. and X.H.E. for 3 days could lead to highly detectable necrosis.

\section{E. royleana extracts induced cell cycle arrest of $\mathrm{CMGT}$ cells} Whether X.E.E. and X.H.E. modulate the cell cycle progression in cMGT cells was next tested. After 3 days of X.E.E. and X.H.E. treatment on MPG and CMT1 cells, the G1/S phase population decreased, and the G2/M phase increased in a dose-dependent manner compared with control cells (Fig. 4). Therefore, these results suggest that X.E.E. and X.H.E. cause cell cycle arrest at the G2/M phase in cMGT cells. Though cMGT cells treating $E$. royleana was found a significantly reduced cell number on day 1, 3 and 5 (Fig. 1), no significant apoptosis was observed for 2 days of X.E.E. and X.H.E. incubation. Analyzing these cells with annexin $\mathrm{V}$ assay revealed few apoptotic cells (Fig. 5a), and the levels of caspase 3, Bax (Bcl-2-associated $\mathrm{X}$ protein), and $\mathrm{Bcl} 2$ (B-cell lymphoma 2) exposed to X.E.E. and X.H.E also did not increase in MPG cells (Fig. 5b). 

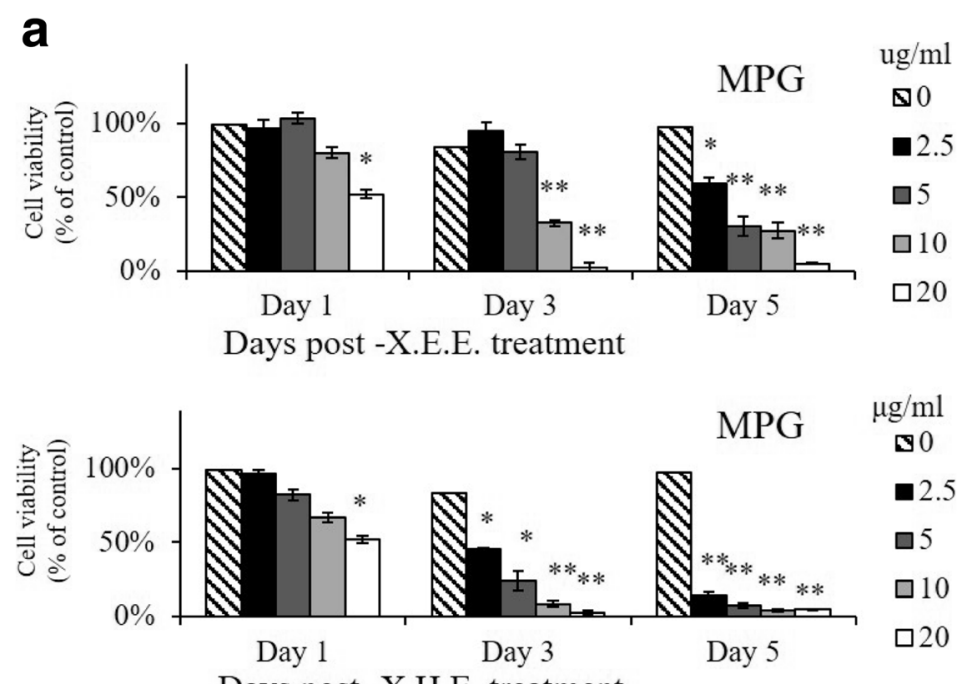

Days post -X.H.E. treatment

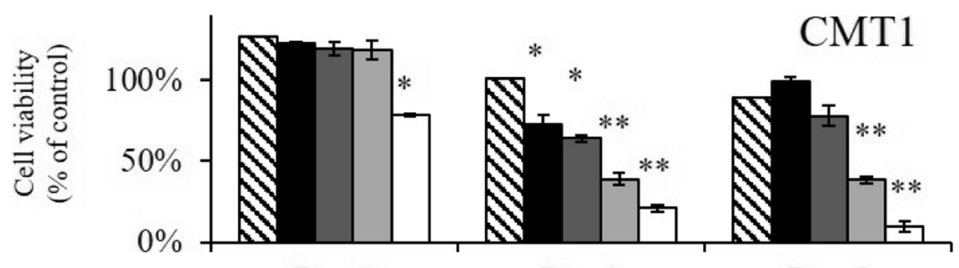

Day 1

Day 3

Day 5

Days post -X.E.E. treatment

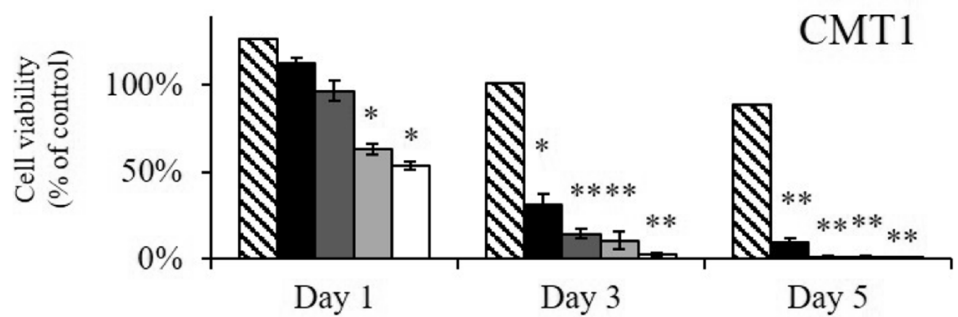

Days post -X.H.E. treatment

b
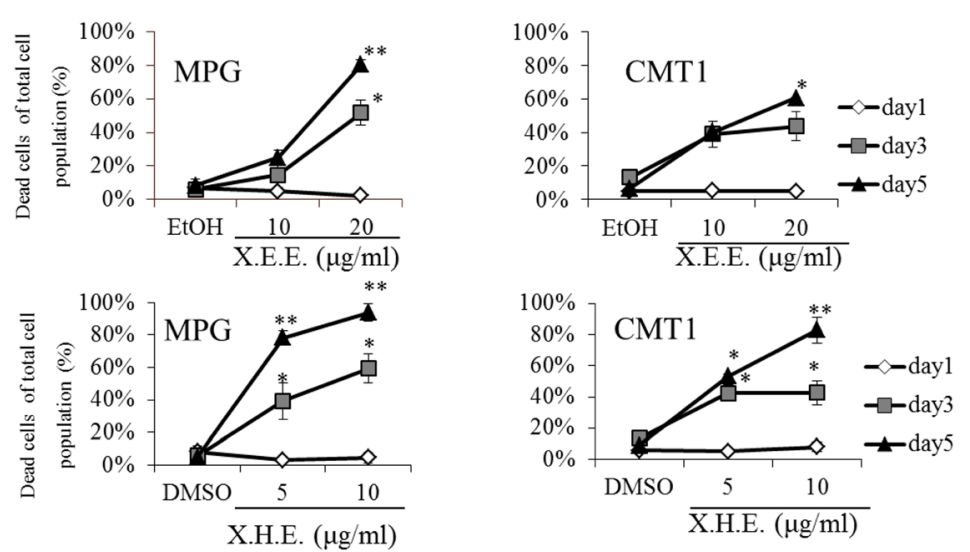

Fig. 1 (See legend on next page.) 
(See figure on previous page.)

Fig. 1 Anti-proliferative effect of E. royleana extracts on cMGT cells. (a) MPG and CMT1 cells treated with X.E.E. and X.H.E. from 2.5 to $20 \mu \mathrm{gg} / \mathrm{mL}$ for 1, 3, and 5 days. Cell viability was detected through WST1 assay. (b) MPG and CMT1 cells treated with X.E.E. and X.H.E. from 5 to $20 \mu \mathrm{g} / \mathrm{mL}$ for 1 ,

3 , and 5 days. Dead cells were detected by the trypan blue exclusion. Each column or point represents the means \pm SDs of experiments

performed using triplicate samples. ${ }^{*}: p<0.05 ;{ }^{* *}: p<0.01$

\section{Autophagy was implicated in E. royleana-treated cMGT cells}

The minimal levels of apoptosis in E. royleana exposing cMGT cells has drawn our attention to inspect the possible role of autophagy in this condition. The formation of autophagic vesicles can be observed when the autosome fuses with lysosome via acridine orange (AO) staining. AO crosses into lysosomes (and other acidic compartments) and becomes protonated. The protonated dye stacks and stacked acridine orange emits in the red range. Acridine orange not in an acidic compartment emits as green. The results showed MPG and CMT1 cells treated with $10 \mu \mathrm{g} / \mathrm{mL}$ X.E.E. or $5 \mu \mathrm{g} / \mathrm{mL}$ X.H.E. to indicate the significant autophagic vesicle formation on day 2 (Fig. 6a and c). Quantified data by flow cytometry also showed the similar results (Fig. 6b and d). The decreased expression of p53 and increased expression of autophagosome marker LC3 (microtubuleassociated light chain 3) (Fig. 6e) proved that autophagy was indeed involved in this process.

Blocking autophagy was suggested to sensitize cancer cells to apoptosis [16]. We wondered if blocking autophagy could further enhance the antitumor effect of $E$. royleana extracts. Pretreating the autophagic inhibitor Baf as well as culturing cells with X.E.E. and X.H.E. could significantly inhibit cell growth in both cancer cell lines to reveal autophagy has rescued E. royleana-exposed CMT cells from even more severe cell death (Fig. 7).

\section{E. royleana inhibited tumor growth in vivo}

To assess the effects of E. royleana extract on tumor growth in vivo, CMT1 cells were subcutaneously injected into nude mice. Oral administration of X.H.E. every 2-4 days did not affect the body weights of the mice (Fig. 8a); however, the tumor volumes were significantly lower in the X.H.E.-treated mice (Fig. 8b).

Table $1 \mathrm{IC}_{50}$ values of X.E.E. and X.H.E. on CMGT cell lines, canine MDCK, and non-primate Marc145, and Vero cells

\begin{tabular}{lllllll}
\hline \multicolumn{1}{l}{ IC50 $(\mu \mathrm{g} / \mathrm{ml})^{\mathrm{a}}$} \\
\hline & MPG & CMT1 & & MDCK & Marc145 & Vero \\
\hline X.E.E. & $12 \pm 3.1$ & $14 \pm 5.2$ & X.E.E. & $98 \pm 6.7$ & $94 \pm 7.9$ & $68 \pm 9.2$ \\
X.H.E. & $3.5 \pm 1.5$ & $4.5 \pm 2.5$ & X.H.E. & $36 \pm 8.3$ & $33 \pm 9.2$ & $16 \pm 7.3$
\end{tabular}

${ }^{\mathrm{a}}$ Triplicate experiments were performed when cells were treated for $72 \mathrm{~h}$ with triplicate wells for each treatment
Necrotic areas in tumor tissue were discovered, and tumor cells exhibited shrinkage, nuclear condensation, and fragmentation, whereas the vehicle-treated control group exhibited normal nuclear morphology characterized by a diffuse chromatin structure (Fig. 8c-g). These results demonstrate that X.H.E. reduces the size of solid tumors and induces tumor cell necrosis in CMT1 cellinoculated nude mice.

\section{Discussion}

This study demonstrated E. royleana extract triggered necrosis and arrested cell cycle in cMGT cells to inhibit the development of canine mammary tumors. We also found when combined with autophagy inhibitors, it could further induce apoptosis and potentiate the antitumor efficacy of E. royleana. These results indicated the extracts of E. royleana appear to be promising candidates for cMGT treatment.

E. royleana induced significant cell death in cMGT cells, we further considered the main cell death mechanisms: necrosis, apoptosis, and autophagy [17]. Because the release of LDH was highly detectable and staining with AO indicated increased prominent autophagic vesicle formation, we could confirm that necrosis and autophagy were involved in the E. royleana treatment of cMGT cells. Surprisingly, few annexin $\mathrm{V}$-positive cells and little change in apoptosis-related proteins caspase $3, \mathrm{Bcl} 2$, and Bax in cMGT cells during $E$. royleana treatment indicated that no obvious apoptosis was involved in our experimental settings.

Numerous studies have revealed the cross-talk among necrosis, apoptosis, and autophagy [18, 19]. Autophagy and apoptosis share certain signaling pathways and regulate each other to maintain cellular homeostasis [14]. In response to various stress signals, tumor suppressor protein p53 acts as a potent inducer of apoptosis and can also induce autophagy. Autophagy was found possibly to stop cells from undergoing apoptosis by preventing mitochondrial outer membrane permeabilization (MOMP) via blocking the activation of $\operatorname{Bax}[16,20]$. Upregulation of autophagy in growth factor withdrawal cells can allow cell survival [21] by inhibiting apoptosis. To sum up, autophagy is crucial to cell fates and can protect cells from apoptotic stimuli.

When adding autophagy inhibitor to cMGT cells treated with E. royleana, apoptosis sensitivity was 


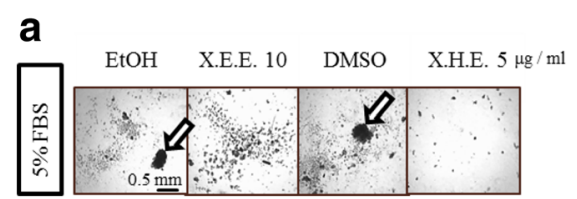

b
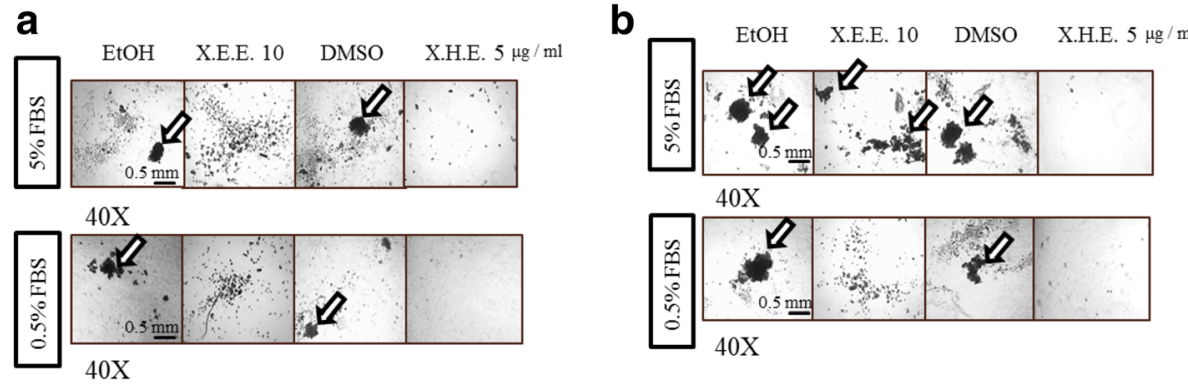

C

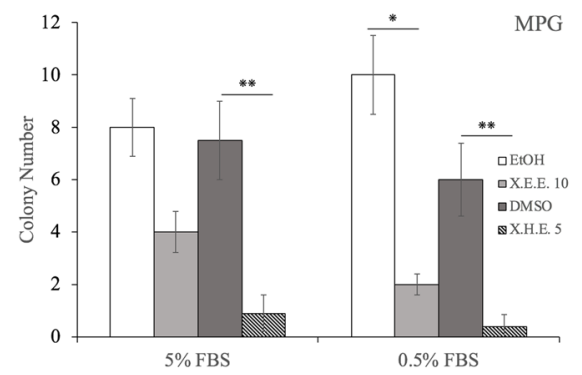

d

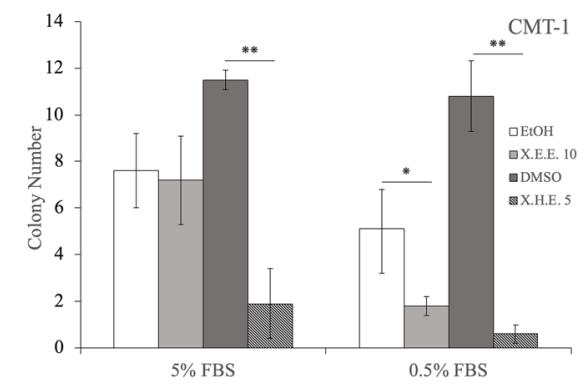

Fig. 2 Colony formation of cMGT cell lines after exposure to different concentrations of X.E.E. and X.H.E. Microscope images reveal no apparent colony formation in (a) MPG cells and (b) CMT1 cells after incubation of X.H.E. $5 \mu \mathrm{g} / \mathrm{mL}$ for 14 days. Quantification of the colony number of (c) MPG cells and (d) CMT1 cells in five images is illustrated by bar charts. Each column represents the means \pm SDs. *: $p<0.05$; ${ }^{* *}: p<0.01$

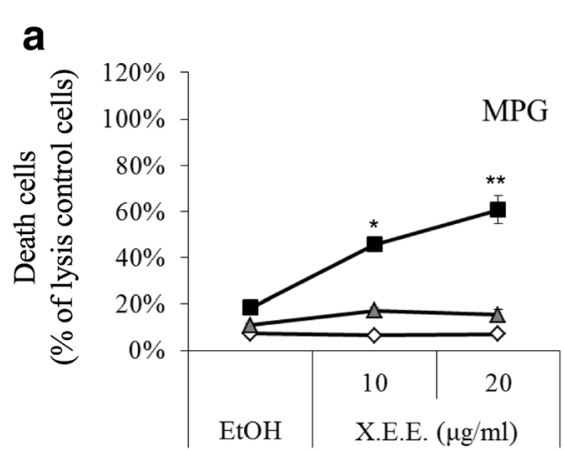

c

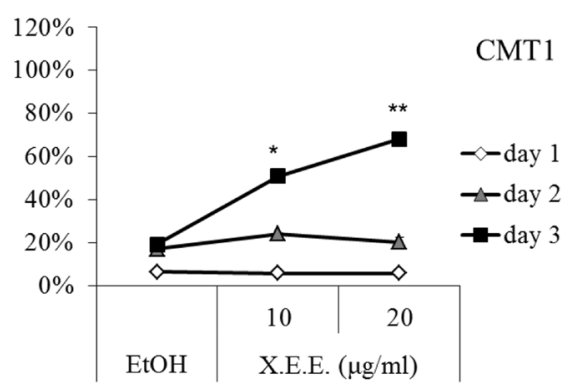

b

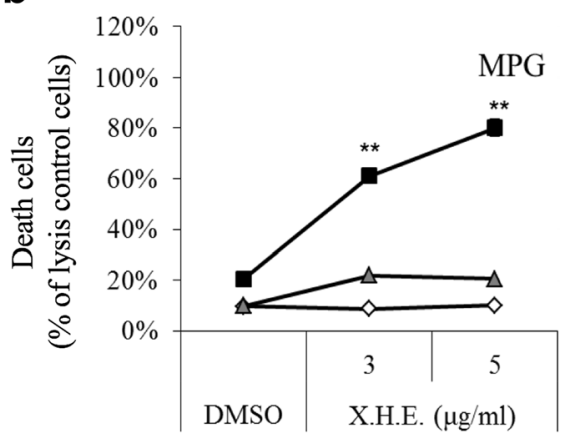

d

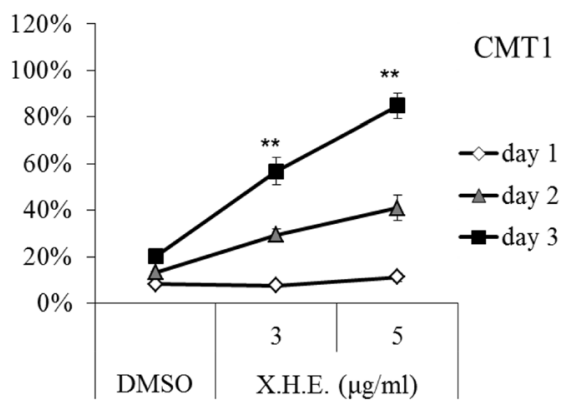

Fig. 3 E. royleana induced necrotic cell death of CMGT cells. MPG cells treated with (a) X.E.E. and (b) X.H.E.; CMT1 cells treated with (c) X.E.E. and (d) X.H.E. for 1, 2, and 3 days. The amount of LDH released is expressed as a percentage of necrotic cells. Each point represents the means \pm SDs of experiments performed using triplicate samples. ${ }^{*}: p<0.05 ;{ }^{* *}$ : $p<0.01$ 

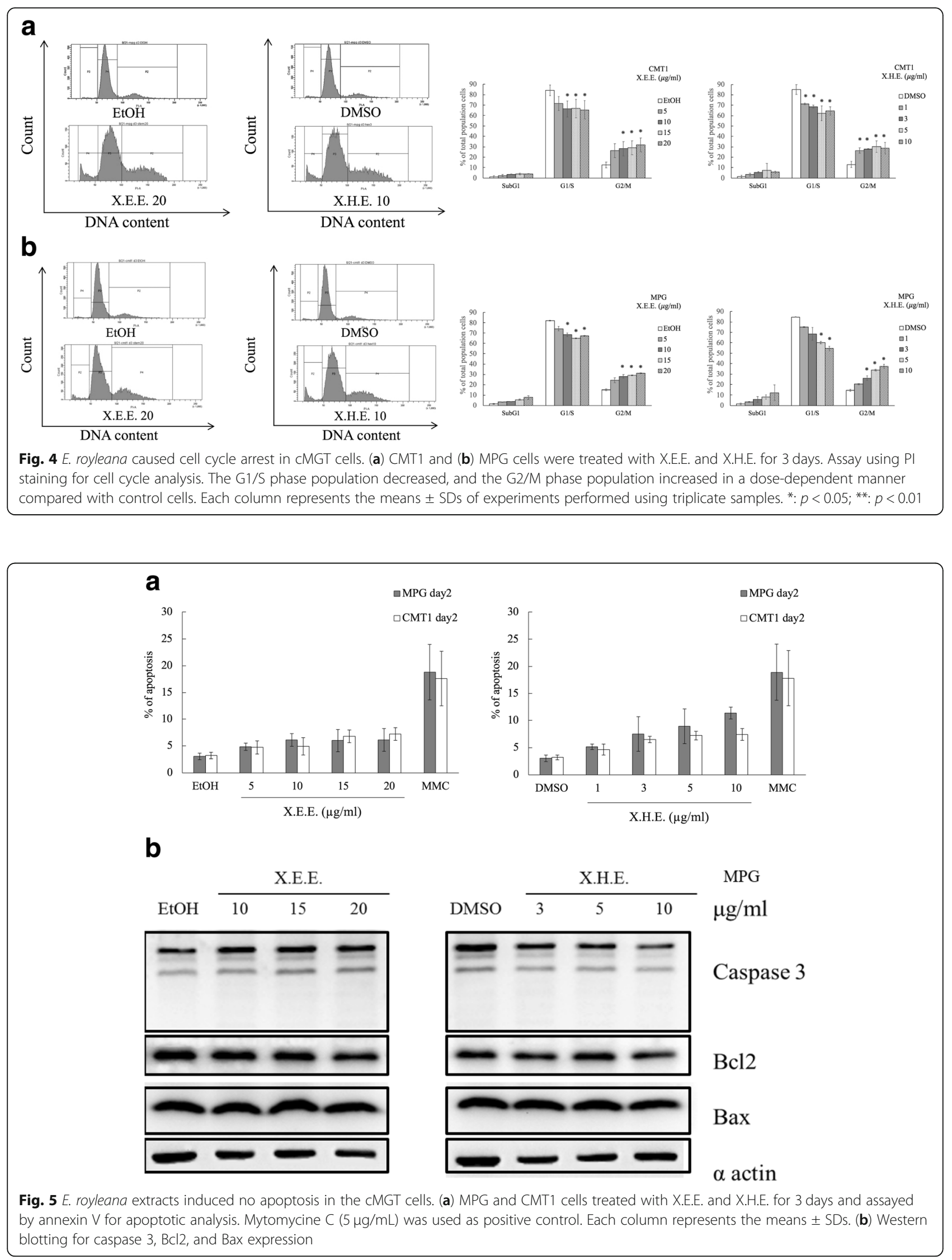


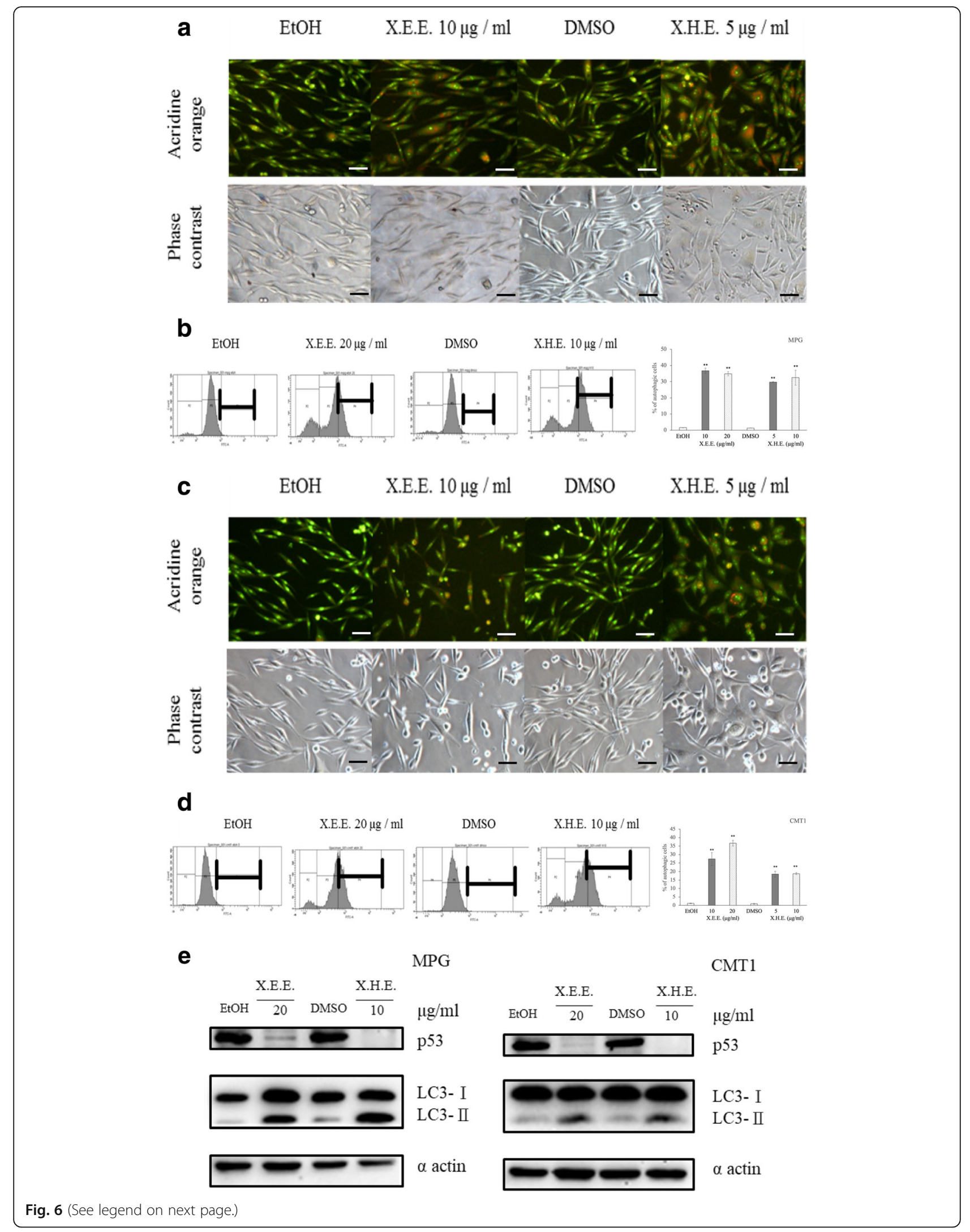


(See figure on previous page.)

Fig. 6 E. royleana induced autophagy in cMGT cells. (a) (b) MPG and (c) (d) CMT1 cells were treated with $10 \mu \mathrm{g} / \mathrm{mL}$ X.E.E. and $5 \mu \mathrm{g} / \mathrm{mL}$ X.H.E. for 2 days; staining with $\mathrm{AO}$ increased the number of orange-colored cells under the fluorescence microscope. Cells were also analyzed through flow cytometry. Each column represents the means \pm SDs. (e) Autophagy-related marker LC3 II and cytoplasmic p53 expression were influenced by X.E.E. and X.H.E. treatment. ${ }^{* *}: p<0.01$

increased and therefore caused a large amount of cell death. A clearer link between autophagy and apoptosis has been reported recently. Autophagy imbalance contributes to high autophagy-regulating transcription factor FOXO3a, resulting in the stimulation of the proapoptotic BBC3/PUMA (Bcl2-binding component 3/ p53 upregulated modulator of apoptosis) gene to cause apoptosis sensitization [22].

The combination of autophagy inhibitor with different anticancer drugs can increase the likelihood of cancer cell death [23]. At present, chloroquine (CQ) and hydroxychloroquine are the only autophagy inhibitors available in clinical practice in human medicine.
By deacidifying the lysosome and blocking the fusion of autophagosomes, these drugs inhibit tumor cell growth or induce tumor cell death [13]. Clinical evidence of glioblastoma treatment involving autophagy inhibitor has received considerable attention recently. Treatment with CQ in conjunction with radiation therapy and the alkylating agent temozolomide demonstrated a statistically significant prolonged median survival time compared with control patient groups [24]. Although the efficacy may vary with different cancer types, a systematic review and meta-analysis indicated that autophagy-inhibitor-based therapy has the optimal treatment response and may provide a a
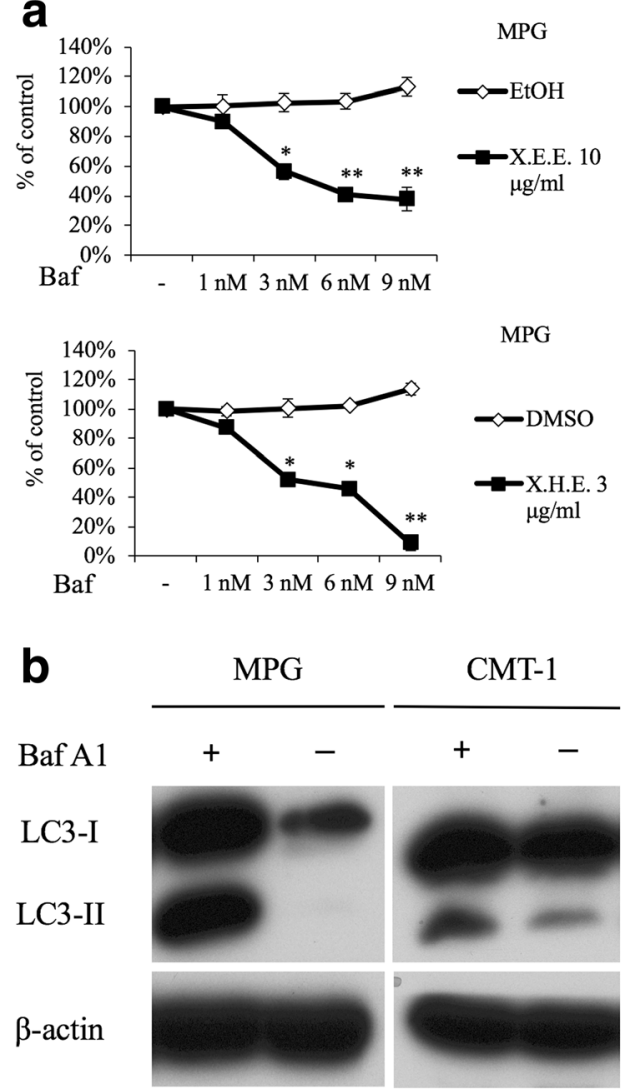
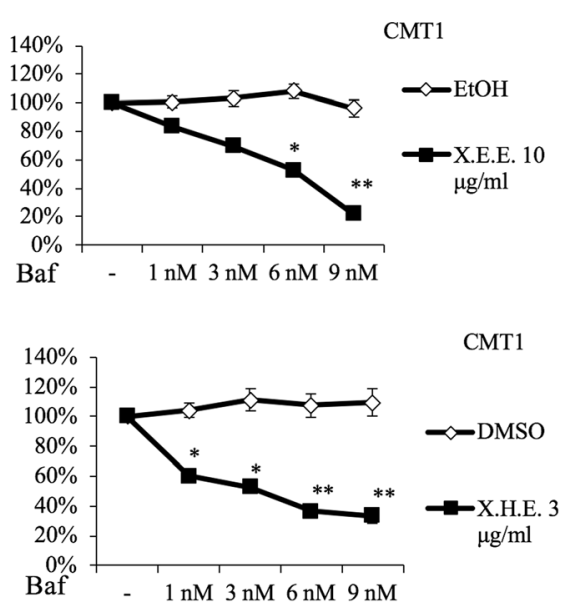

Fig. 7 Blocking autophagy enhanced X.E.E. and X.H.E cell death. (a) Pre-culture cells with different concentration of autophagy inhibitor, Baf A1, then culture MPG and CMT1 cells with X.E.E. $10 \mu \mathrm{g} / \mathrm{ml}$ or X.H.E. $3 \mu \mathrm{g} / \mathrm{ml}$ for 2 days. Cell viability was determined after 2 days by WST1 assay. (b) The cells were treated with bafilomycin (Baf) (6 nM) for $4 \mathrm{~h}$ and microtubule-associated protein 1 light chain 3 (LC3-I \& II) expression was measured to demonstrate the autophagy-blocking ability of Baf A1 

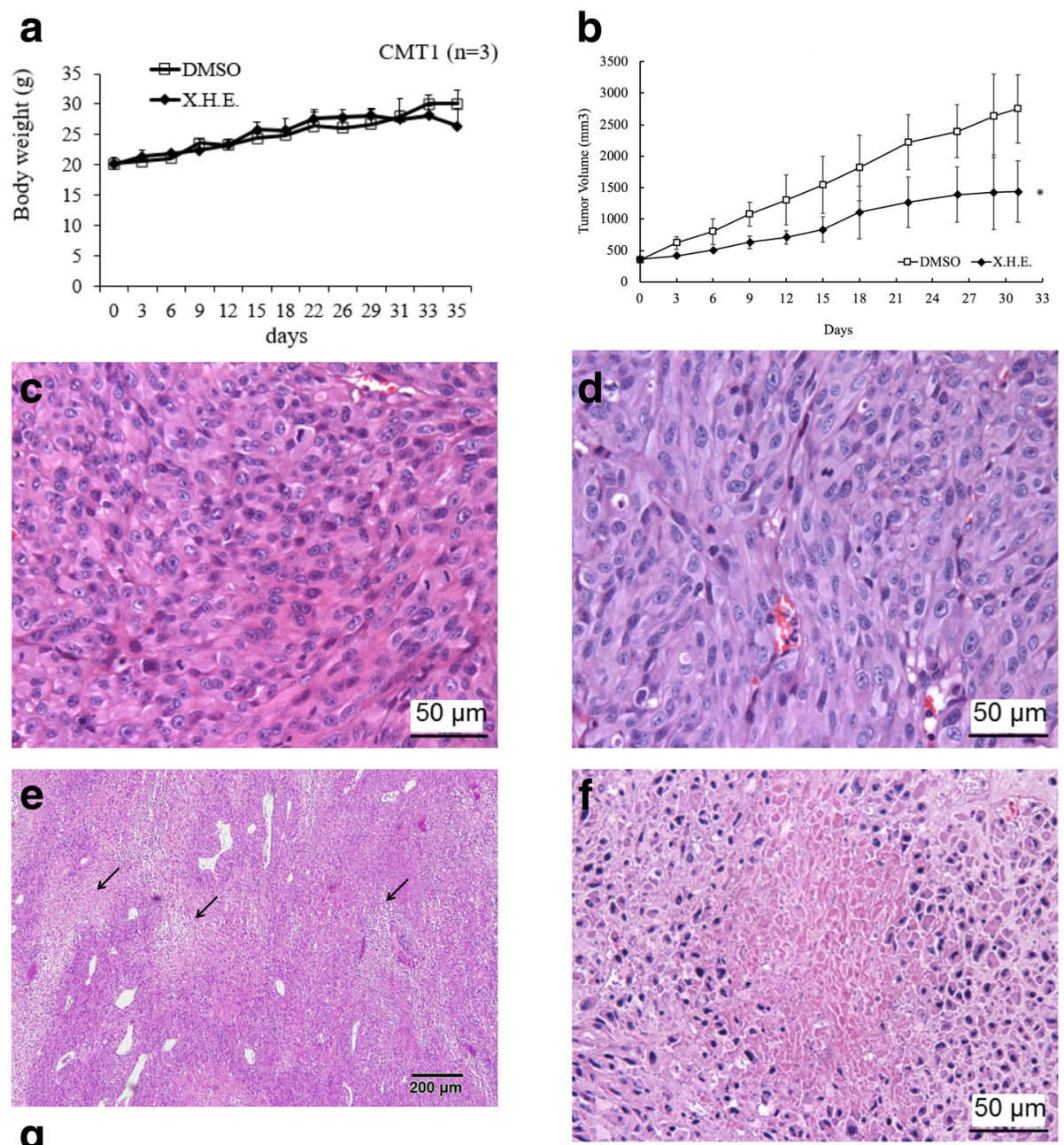

g

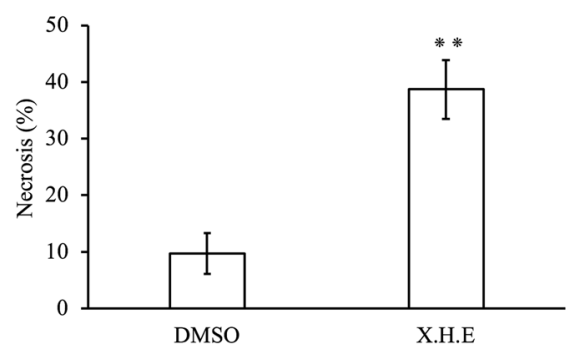

Fig. 8 E. royleana inhibited the growth of xenograft CMGT. (a) Changes in mouse body weight. (b) X.H.E. inhibited the growth of tumor volumes in vivo. Euthanized CMT1-bearing nude mice after treatment with X.H.E. or vehicle-treated control group. Hematoxylin and eosin-stained tumor tissue slides were photographed. In the vehicle-treated group, (c) saline and (d) DMSO exhibited normal nuclear morphology characterized by diffuse chromatin structures. X.H.E-treated group exhibited (e) necrosis in tumor tissue (arrow) and (f) cell shrinkage, nuclear condensation, increased darkness, and fragmentation. (g) Quantification of necrotic area in tumors. *: $p<0.05$; ${ }^{*}: p<0.01$

new strategy for the treatment of cancer [25]. Thus, the application of autophagy-targeted therapy appears to be a feasible clinical strategy in appropriately selected patient populations. We have recognized that treating cMGT cells with a combination of extracts of E. royleana and the autophagy inhibitor Baf can significantly enhance tumor cell death. Based on this evidence, further investigation uncovering the mechanism of autophagy in cMGTs could offer a promising future for new cancer treatment.

\section{Conclusions}

This study clarifies the antitumor effect of E. royleana on cMGTs in vitro and in vivo. Blocking autophagy was also found to further increase cell death by triggering apoptosis in E. royleana-treated tumors. We hope 
further studies can be conducted to evaluate the clinical applications of E. royleana extracts and autophagy inhibitors for canine mammary tumors.

\section{Methods}

\section{E. royleana extracts and cell culture}

The ethanol extract of E. royleana (X.E.E.) and hexane extract of E. royleana (X.H.E.) were kindly provided by Dr. Tsun-Yung Kuo's laboratory (National Ilan University, Taiwan). Marc145, and cMGT cell lines, CMT1 [26] and MPG [27] were kindly provided by Dr. ChungTien Lin's laboratory (School of Veterinary Medicine, National Taiwan University). MDCK, Vero, and Marc145 cells were purchased from the Bioresource Collection and Research Center in Taiwan. All cell lines were cultured with Dulbecco's Modified Eagle's Medium (DMEM) containing 10\% fetal bovine serum (FBS) (Thermo-Fisher Scientific, USA) and 1\% antibiotic-antimycotic solution (Roche, Germany) in a humidified incubator with $5 \% \mathrm{CO}_{2}$ at $37^{\circ} \mathrm{C}$.

\section{Cell viability and $\mathrm{LDH}$ cytotoxic assay}

Cells $\left(3 \times 10^{3}\right)$ were treated with the indicated concentration of X.E.E. or X.H.E. for various periods. The cell viability was determined through WST1 assay (Roche, Germany) after the treatment. The effect of the X.E.E. and X.H.E. on the viabilities of cMGT cells were expressed as the cell viability using the formula: \% of control cells $=[(\mathrm{OD}$ of test samples $-\mathrm{OD}$ of blanks $)] /$ $[(\mathrm{OD}$ of control samples - OD of blanks) $] \times 100 \%$. CytoTox 96 nonradioactive cytotoxicity assay (Promega, USA) was used to measure the cytotoxic effects of X.E.E. and X.H.E. according to the manufacturer's instructions. The amount of lactate dehydrogenase (LDH) release reflects the percentage of cells that underwent necrosis.

\section{Trypan blue exclusion}

Cells $\left(2 \times 10^{5}\right)$ were seeded in the 6-well plate for overnight and then treated with various concentrations of X.E.E. and X.H.E. for different intervals. This was followed by staining with trypan blue dye. The dead cells were counted using a light microscope and calculated with the formula: \% of dead cells $=[$ (total dead cells / total live and dead cells)] $\times 100 \%$.

\section{Soft agar assay}

Cells $\left(2.5 \times 10^{3}\right)$ were seeded in $0.35 \%$ agar (Sigma-Aldrich, USA) on top of $0.7 \%$ bottom agar in a 24-well plate containing X.E.E. or X.H.E. where indicate. Once a week the plates were overlaid with $0.5 \mathrm{ml} \mathrm{low}-(0.5 \%$ FBS) and high- (5\% FBS) serum medium containing X.E.E. or X.H.E. with the indicated concentration. Colonies were counted after 14 days by a light microscope.

\section{Apoptosis analysis}

Annexin V-fluorescein isothiocyanate (FITC) apoptosis detection (Strong Biotech, Taiwan) and sub-G1 analysis were performed by flow cytometry. Cells $\left(4 \times 10^{5}\right)$ were treated with the indicated concentration of X.E.E. or X.H.E. for various periods and using mitomycin $\mathrm{C}(5 \mu \mathrm{g} /$ $\mathrm{mL}$ ) as a positive control. Both early apoptotic (annexin $\mathrm{V}$-positive, propidium iodide (PI)-negative) and late apoptotic (annexin V-positive and PI-positive) cells were included in cell death determinations. For sub-G1 analysis, after X.E.E. or X.H.E. treatment, the cells were fixed and stained with propidium iodide utilizing the PI/ RNase Staining Buffer (BD Biosciences, USA) according to the manufacturer's instructions.

\section{Autophagosome staining with acridine orange}

Acridine orange $(\mathrm{AO})$ cell staining was performed according to the published procedures [28]. Cells $\left(2 \times 10^{5}\right)$ were treated with the indicated concentration of X.E.E. or X.H.E. for $48 \mathrm{~h}$. Then the cells were harvested and stained with $2 \mu \mathrm{g} / \mathrm{mL}$ AO for (Sigma-Aldrich, USA) 5 min incubation. The red or green emitted fluorescence were observed or measured by the fluorescence microscope and flow cytometer.

\section{Western blotting}

The cell lysates treated with X.E.E. or X.H.E. at the indicated concentrations for various periods of time were prepared for immunoblotting of LC3, p53, Caspase 3, Bcl2, Bcl2-associated X protein (Genetex, USA). Western blot analysis was performed as previously reported [29]. The original blots can be referred in the additional file 1 .

\section{Blocking autophagy}

Cells $\left(3 \times 10^{3}\right)$ were precultured with different concentrations (1-9 nM) of autophagy inhibitor, bafilomycin A1 (Baf) (Sigma-Aldrich, USA) for $2 \mathrm{~h}$; subsequently the medium was changed with $10 \mu \mathrm{g} / \mathrm{mL}$ X.E.E. and $3 \mu \mathrm{g} / \mathrm{mL}$ X.H.E., and the cells were incubated for 3 days. Cell viability was determined after 3 days through WST1 assay.

\section{CMGT xenograft model}

Male NCr athymic nude mice aged 8-10 weeks were obtained from National Laboratory Animal Center (Taipei, Taiwan). The mice were maintained in accordance with protocols approved by the Institutional Animal Care and Use Committee of National Taiwan University (IACUC No. NTU-100-EL-90). $5 \times 10^{6}$ cells were inoculated into each mouse. Tumor volume based on caliper measurements were calculated by the modified ellipsoidal formula: Tumor volume $=1 / 2$ (length $\times$ width $^{2}$ ). When CMT1 cells were inoculated subcutaneously and the tumor is reached $300-500 \mathrm{~mm}^{3}$, mice $(N=6$ in each treatment) were randomized distributed in each group 
and received X.H.E. (10 mg $/ \mathrm{kg}$ ) p.o. every $2-4$ days. Controls received vehicle. The duration of the treatment was 5 weeks and then the animals were euthanized by $\mathrm{CO}_{2}$ overdose exposure. The tumor samples were collected after the treatment. Three independent experiments were conducted and the significance was analyzed in each individual test.

\section{Statistical analysis}

Results were expressed as mean \pm standard deviation. The data were analyzed by a two- way ANOVA followed by post-hoc Tukey HSD test (GRAPHPAD PRISM, GraphPad Software Inc., USA). Differences with $p$-values ${ }^{*} p<$ $0.05,{ }^{* * *} p<0.01$ were considered statistically significant.

\section{Supplementary information}

Supplementary information accompanies this paper at https://doi.org/10 1186/s12917-020-02408-1.

Additional file 1. The original blots for the figures.

\section{Abbreviations}

$\mathrm{AO}$ : Acridine orange; $\mathrm{BBC} 3$ : $\mathrm{BCl}-2$-binding component 3; $\mathrm{BCl} 2$ : B-cell lymphoma 2; Baf: Bafilomycin A1; Bax: Bcl2-Associated X Protein; CQ: Chloroquine; CMGTs: Canine mammary gland tumors; Euphorbia royleana: E. royleana; FBS: Fetal bovine serum; FITC: Fluorescein isothiocyanate; FOXO3a: Forkhead box $\mathrm{O}_{3} ; \mathrm{IC}_{50}$ : The half maximal inhibitory concentration; LC3: Microtubule-associated light chain 3; LDH: Lactate dehydrogenase; MOMP: Mitochondrial outer membrane permeabilization; PI: Propidium iodide; PUMA: p53 upregulated modulator of apoptosis; X.E.E.: Ethanol extract of E. royleana; X.H.E.: Hexane extract of E. royleana

\section{Acknowledgements}

Not applicable.

\section{Authors' contributions}

The experiments and manuscript writing were conducted and analyzed by $\mathrm{YH}, \mathrm{CC}$, and $\mathrm{CH}$. The methodology was provided by $\mathrm{TK}, \mathrm{CL}$, and $\mathrm{AL}$. $\mathrm{CL}$ was responsible for conceptualization, supervision, writing-review, and funding acquisition. All authors have read and approved the final version of the manuscript.

\section{Funding}

This work was supported by Ministry of Science and Technology (102-2313B-002-031-MY3), and Council of Agriculture (107AS-22.1.6-AD-U1(8) \& 108AS21.1.7-AD-U1(8)) in Taiwan for supporting the staff costs, the preparation of experimental materials, and the manuscript editing.

\section{Availability of data and materials}

The datasets used and/or analyzed during the current study are available from the corresponding author on reasonable request.

\section{Ethics approval and consent to participate}

The mice used in this study were maintained in accordance with protocols approved by the Institutional Animal Care and Use Committee of National Taiwan University (IACUC No. NTU-100-EL-90) that was organized according to the "Animal Protection Act" authorized by Council of Agriculture, Taiwan. The duration of the treatment was 5 weeks and then the animals were sacrificed by $\mathrm{CO}_{2}$ overdose exposure.

\section{Consent for publication}

Not applicable.

\section{Competing interests}

The authors declare that they have no competing interests.

\section{Author details}

${ }^{1}$ Department and Graduate Institute of Veterinary Medicine, School of Veterinary Medicine, National Taiwan University, No.1 Sec.4 Roosevelt Rd, Taipei 10617, Taiwan. ${ }^{2}$ Institute of Molecular Medicine and Bioengineering, National Chiao Tung University, Hsinchu City 30068, Taiwan. ${ }^{3}$ Department of Biotechnology and Animal Science, National Ilan University, Ilan 26041,

Taiwan. ${ }^{4}$ Animal Cancer Center, College of Bioresources and Agriculture, National Taiwan University, Taipei 10617, Taiwan.

Received: 9 October 2019 Accepted: 2 June 2020

Published online: 12 June 2020

\section{References}

1. Andrade FH, Figueiroa FC, Bersano PR, Bissacot DZ, Rocha NS. Malignant mammary tumor in female dogs: environmental contaminants. Diagn Pathol. 2010;5:45.

2. Siegel RL, Miller KD, Jemal A. Cancer statistics, 2015. CA Cancer J Clin. 2015; 65(1):5-29.

3. Moe L. Population-based incidence of mammary tumours in some dog breeds. J Reprod Fertil Suppl. 2001;57:439-43.

4. Pastor N, Caballé NC, Santella M, Ezquerra LJ, Tarazona R, Duran E. Epidemiological study of canine mammary tumors: age, breed, size and malignancy. Austral J Vet Sci. 2018;50:143-7.

5. Nordin ML, Osman AY, Shaari R, Arshad MM, Kadir AA, Reduan MFH. Recent overview of mammary cancer in dogs and cats: classification, risk factors and future perspectives for treatment. IOSR J Agri Vet Science (IOSR-JAVS). 2017;10:64-9.

6. Galvez J, Zarzuelo A, Crespo ME, Lorente MD, Ocete MA, Jimenez J. Antidiarrhoeic activity of Euphorbia hirta extract and isolation of an active flavonoid constituent. Planta Med. 1993;59(4):333-6.

7. Patil SB, Magdum CS. Determination of LC50 values of extracts of Euphorbia hirta Linn and Euphorbia neriifolia Linn using brine shrimp lethality assay. Asian J Res Pharm Sci. 2011;1:42-3.

8. Amirghofran Z, Malek-hosseini S, Gholmoghaddam H, Kalalinia F. Inhibition of tumor cells growth and stimulation of lymphocytes by Euphorbia species. Immunopharmacol Immunotoxicol. 2011;33(1):34-42.

9. Ashraf A, Sarfraz RA, Rashid MA, Shahid M. Antioxidant, antimicrobial, antitumor, and cytotoxic activities of an important medicinal plant (Euphorbia royleana) from Pakistan. J Food Drug Anal. 2015;23(1):109-15.

10. Jiao W, Dong W, Li Z, Deng M, Lu R. Lathyrane diterpenes from Euphorbia lathyris as modulators of multidrug resistance and their crystal structures. Bioorg Med Chem. 2009;17(13):4786-92.

11. Lindqvist LM, Simon AK, Baehrecke EH. Current questions and possible controversies in autophagy. Cell Death Discov. 2015;1:15036.

12. Rouschop KM, Wouters BG. Regulation of autophagy through multiple independent hypoxic signaling pathways. Curr Mol Med. 2009;9(4):417-24.

13. Levy JMM, Towers CG, Thorburn A. Targeting autophagy in cancer. Nat Rev Cancer. 2017;17(9):528-42

14. Rubinstein $A D$, Kimchi $A$. Life in the balance - a mechanistic view of the crosstalk between autophagy and apoptosis. J Cell Sci. 2012;125(Pt 22): 5259-68.

15. Rubinsztein DC, Codogno P, Levine B. Autophagy modulation as a potential therapeutic target for diverse diseases. Nat Rev Drug Discov. 2012;11(9):709-30.

16. Thorburn J, Andrysik Z, Staskiewicz L, Gump J, Maycotte P, Oberst A, Green DR, Espinosa JM, Thorburn A. Autophagy controls the kinetics and extent of mitochondrial apoptosis by regulating PUMA levels. Cell Rep. 2014;7(1):45-52.

17. Galluzzi L, Vitale I, Aaronson SA, Abrams JM, Adam D, Agostinis P, Alnemri ES, Altucci L, Amelio I, Andrews DW, et al. Molecular mechanisms of cell death: recommendations of the nomenclature committee on cell death 2018. Cell Death Differ. 2018;25(3):486-541.

18. Eisenberg-Lerner A, Bialik S, Simon HU, Kimchi A. Life and death partners: apoptosis, autophagy and the cross-talk between them. Cell Death Differ. 2009;16(7):966-75.

19. Singh R, Letai A, Sarosiek K. Regulation of apoptosis in health and disease: the balancing act of BCL-2 family proteins. Nat Rev Mol Cell Biol. 2019;20(3): 175-93.

20. Tait SW, Green DR. Mitochondria and cell death: outer membrane permeabilization and beyond. Nat Rev Mol Cell Biol. 2010;11(9):621-32.

21. Lum JJ, Bauer DE, Kong M, Harris MH, Li C, Lindsten T, Thompson CB. Growth factor regulation of autophagy and cell survival in the absence of apoptosis. Cell. 2005;120(2):237-48. 
22. Fitzwalter BE, Towers CG, Sullivan KD, Andrysik Z, Hoh M, Ludwig M, O'Prey J, Ryan KM, Espinosa JM, Morgan MJ, et al. Autophagy inhibition mediates apoptosis sensitization in Cancer therapy by relieving FOXO3a turnover. Dev Cell. 2018:44(5):555-65 e553.

23. Kimura T, Takabatake Y, Takahashi A, Isaka Y. Chloroquine in cancer therapy: a double-edged sword of autophagy. Cancer Res. 2013;73(1):3-7.

24. Briceno E, Reyes S, Sotelo J. Therapy of glioblastoma multiforme improved by the antimutagenic chloroquine. Neurosurg Focus. 2003;14(2):e3.

25. Xu R, Ji Z, Xu C, Zhu J. The clinical value of using chloroquine or hydroxychloroquine as autophagy inhibitors in the treatment of cancers: a systematic review and meta-analysis. Medicine (Baltimore). 2018;97(46): e12912.

26. Lee JJ, Chen PB, Yang SH, Cheng CH, Chueh LL, Pang VF, Hsiao M, Lin CT. Effect of the VP3 gene of chicken anemia virus on canine mammary tumor cells. Am J Vet Res. 2007;68(4):411-22.

27. Lee JL, Chang CJ, Chueh LL, Lin CT. Secreted frizzled related protein 2 (sFRP2) decreases susceptibility to UV-induced apoptosis in primary culture of canine mammary gland tumors by NF-kappaB activation or JNK suppression. Breast Cancer Res Treat. 2006;100(1):49-58.

28. Klionsky DJ, Abdelmohsen K, Abe A, Abedin MJ, Abeliovich H, Acevedo Arozena A, Adachi H, Adams CM, Adams PD, Adeli K, et al. Guidelines for the use and interpretation of assays for monitoring autophagy (3rd edition). Autophagy. 2016;12(1):1-222.

29. Lin CS, Chen MF, Wang YS, Chuang TF, Chiang YL, Chu RM. IL-6 restores dendritic cell maturation inhibited by tumor-derived TGF-beta through interfering Smad 2/3 nuclear translocation. Cytokine. 2013;62(3):352-9.

\section{Publisher's Note}

Springer Nature remains neutral with regard to jurisdictional claims in published maps and institutional affiliations.

Ready to submit your research? Choose BMC and benefit from:

- fast, convenient online submission

- thorough peer review by experienced researchers in your field

- rapid publication on acceptance

- support for research data, including large and complex data types

- gold Open Access which fosters wider collaboration and increased citations

- maximum visibility for your research: over $100 \mathrm{M}$ website views per year

At $\mathrm{BMC}$, research is always in progress.

Learn more biomedcentral.com/submissions 